\title{
Thrombosis in Coronary Heart Disease ${ }^{\star}$
}

\author{
LAWSON MCDONALD
}

\author{
From the Institute of Cardiology, National Heart Hospital, London W.1, and the Cardiac Department, \\ The London Hospital, London E.1
}

Coronary heart disease or ischaemic heart disease may be defined as coronary arterial disease that results in dysfunction of the heart. Well-recognized presentations are angina pectoris on effort, coronary insufficiency, which may be defined as cardiac pain at rest without the stigmata of cardiac infarction, and cardiac infarction itself, which may be silent. In recent years the cardiac dysrhythmias have been increasingly recognized as initial manifestations of coronary heart disease. A number of patients present with sudden death, and some with cardiomegaly. The last is particularly common in old age.

\section{RISK FACTORS}

The following factors are recognized as placing people at an undue risk of the likelihood of developing the disease. One of the foremost is a first-degree affected relative with the disease (Cassidy, 1946; Gertler and White, 1954; Thomas and Cohen, 1955; Rose, 1964; Slack and Evans, 1966); an important correlation in this respect is an impairment of lipoprotein lipase (Slack et al., 1964). The disease is predominantly one of the male sex (Heberden, 1802; Hedley, 1939), though women after the menopause and after bilateral ovariectomy (Oliver and Boyd, 1959) have the same risk. Hypercholesterolaemia (Gertler, Garn, and Lerman, 1950) crudely reflects the abnormality of lipid metabolism, which is more accurately shown by hyperglyceridaemia (Antonis and Bersohn, 1960). Systemic hypertension is an important contributory cause (Dawber, Moore, and Mann, 1957; Kannel et al., 1961; Dawber et al., 1962), and abnormal carbohydrate metabolism is increasingly recognized as such (Wahlberg, 1962). Abnormalities of platelet behaviour, such as platelet stickiness, also seem important (McDonald and Edgill, 1957); a

* The St. Cyres Lecture of the National Heart Hospital delivered at the Royal College of Physicians, London, November 30, 1966. number of patients have been studied in whom platelet behaviour has been abnormal for periods varying from two years to a few weeks before the development of cardiac infarction ( $\mathrm{L}$. McDonald, 1966, unpublished data). The role of cigarette smoking (Doll and Hill, 1954; Hammond and Horn, 1954) seems certain.

Possible risk factors which have been incriminated by various authors include diet, with an unduly heavy intake of animal fat, sugar, and also protein. Furthermore, those who have large heavy meals have been thought more likely to develop the disease, together with the overweight and the physically inactive. Hyperuricaemia has during recent years become apparent as a risk factor; its possible role was recognized by Allbutt (1915). Kohn and Prozan (1959) found that 70 per cent of patients with cardiac infarction had a raised serum uric acid. Morris, Crawford, and Heady (1961) found that the disease was more prevalent in areas where there was soft as opposed to hard water, and Biörck, Boström, and Widström (1965) found an important and highly significant negative correlation between calcium ion concentration in the water and the statistical group 422 which is "other degenerative heart disease". In the Framingham study it was shown that if a person developed cardiac infarction the spouse was more likely to do so (Dawber et al., 1957). Most of these risk factors apply to groups, and the more precise identification of the person likely to develop ischaemic heart disease seems important.

Occupational risk does appear to produce the possibility of acquired factors. Occupational mortality has been studied by Morris (1962) using the standardized mortality ratio of various groups of occupations (Fig. 1). These ratios are ratios of the national average rate, allowances having been made for differences in age structure and between occupations. The occupation at highest risk was that of 151 the radio and telegraph operators, whose risk rate 
(a)

Standardized mortality ratio

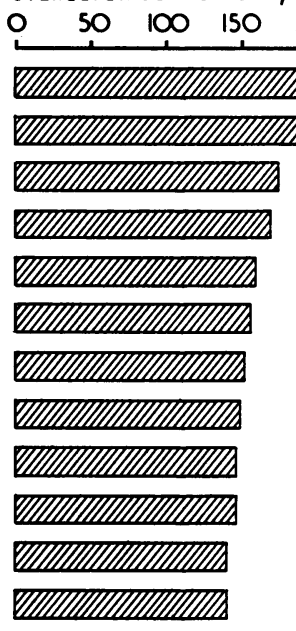

WIIIIIIIIII
Radio $\varepsilon$ Telegraph operators

R.C. Priests,etc.

Harbour officials, Piermasters

Chemists (Scientists)

Doctors

Brokers, Agents, Foctors

Clergymen (C. of E.)

Musicions

Monogers, Directors, in
communicotions

Garment workers

Telephone operators

Proprietors, Manogers and Assistants in Tobacconists, Confectioners and Newsogents

All Males (b)

Standardized mortality ratio

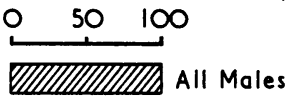

WIIIIIII Makers of Alcoholic drinks

VIIIIIII

Machine assemblers, unskilled

WIIIIIII

Plosterers

WIIIIIIII

Boot ‘ Shoe makers, factory

VIIIIIII

Spinners, piecers-cotton

WIIIIII

WIIIIII

Press tool setters, Machine

Formers setters

VIIIIIII

Builders' labourers a navvies

WIIIIIIS

Vehicle makers \& repoirers

DIIIIII

VIIIIIII

Makers of Bricks, etc.

Window cleaners

VIIIIII

Agricultural workers

B was more than twice normal. Denominational differences appeared to exist: Roman Catholic priests were found to be more likely to develop ischaemic heart disease than clergymen of the Church of England. Doctors also appeared with a high risk rate. The occupations with the lowest risk rates are shown in Fig. 1, the lowest being that of rag, bone, and bottle sorters.

Figures from the London Hospital and the National Autopsy Survey (Morris, 1951; Morris and Crawford, 1961) suggest that it may be thrombosis, as opposed to disease of the arterial wall, that is important in the claimed increase in the incidence of cardiac infarction (Table I).

\section{THROMBOSIS}

It is important, in considering thrombosis in ischaemic heart disease, to differentiate between thrombus-formation and clotting (Poole and French, 1961). A thrombus occurs in vivo, and has a complicated structure of agglutinated platelets and leucocytes, the so-called "white head", to which is attached a meshwork of fibrin with entrapped red cells, which has been called the "red tail". A clot, on the other hand, occurs in vitro, and its structure is uniform; all the blood cells including the platelets
TABLE I

PREVALENCE OF CORONARY ARTERY DISEASE IN MEN AGED 45-54 DYING FROM ACCIDENTS, INFECTIONS, CANCER, ETC.

\begin{tabular}{l|c|c}
\hline & $1908-13$ & $1954-56$ \\
\hline Atheroma of walls of coronary arteries (\%) & 51 & 29 \\
Calcification present (\%) & 17 & $6 \cdot 7$ \\
Occlusion of coronary lumen (\%) & $1 \cdot 3$ & $4 \cdot 8$ \\
Ischaemic myocardial fibrosis (\%) & $0 \cdot 8$ & $3 \cdot 8$ \\
\hline Number of necropsies & 373 & 821 \\
\hline
\end{tabular}

Figures from the London Hospital (1908-13) and the National Autopsy Survey of Great Britian (1954-56), showing the prevalence of coronary artery disease in men aged 45-54 dying from accidents, infections, cancer, etc. Arterial atheroma and calcification appear to have decreased in frequency, and occlusion and ischaemic myocardial fibrosis to have increased, suggesting an increase in thromcardial fibrosis to have increased, sugges
botic occlusion. From Morris (1962).

are distributed at random and none has agglutinated. This difference suggests that there may be factors affecting thrombosis that are not revealed by the usual methods of studying blood coagulation, and, furthermore, that anticoagulant treatment may not be antithrombotic.

Frequency of Thrombosis. What is the incidence of thrombosis in cardiac infarction? Mitchell and Schwartz (1965) separated occlusive lesions of the 
TABLE II

FREQUENCY OF OCCLUDING THROMBI IN CARDIAC INFARCTION *

\begin{tabular}{l|c}
\hline \multicolumn{1}{c|}{ Authors } & Per cent \\
\hline Davenport (1928) & 60 \\
Barnes and Ball (1932) & 69 \\
Gross and Sternberg (1939) & 7 \\
Blumgart et al. (1940) & 90 \\
Master et al. (1941) & 0 \\
Master et al. (1944) & 96 \\
Harrison and Wood (1949) & 93 \\
Snow et al. (1955) & 59 \\
Muri (1956) & 94 \\
Spain and Bradess (1960) & $16-54$ \\
Harland and Holburn (1966) & 91 \\
\hline
\end{tabular}

* Modified from Mitchell and Schwartz (1965).

coronary arteries into occlusion thrombi, recanalizing thrombi, and arterial plaques. They quoted Duguid (1946, 1948) regarding the difficulty in distinguishing between occluding plaques and recanalizing thrombi, and noted that the difference was probably artificial. The reported incidence of thrombosis in cardiac infarction (Table II) varies from 0 to 96 per cent (Davenport, 1928; Barnes and Ball, 1932; Gross and Sternberg, 1939; Blumgart, Schlesinger, and Davis, 1940; Master et al., 1941, 1944; Harrison and Wood, 1949; Snow, Morgan Jones, and Daber, 1955; Muri, 1956; Spain and Bradess, 1960; Harland and Holburn, 1966). Questions arise as to whether authors have differed in their selection of cases, in the techniques and thoroughness of their examinations, and even regarding the possible misinterpretation of data. Muri (1956), in an excellent study, found only 2 of 33 cases that did not have evidence of a fresh thrombotic occlusion, and Harland and Holburn (1966) reported thrombosis in 91 per cent of cases of cardiac infarction. At the very least, thrombosis is important in a small group of cases only, but it is probably so in the vast majority. It may even play an important role in the development of the changes described as atherosclerosis, and it seems a likely final common path of many risk factors. Mitchell and Schwartz (1965) wrote:

\footnotetext{
"It is possible, therefore, that there is an alternative explanation for the observed relationship between the wall disease and thrombosis: thrombi begin to form at certain sites in the coronary tree, as determined by blood flow patterns and this process beginning before the age of 35 in men and at a later age in women. In the majority of patients these thrombi are non-occlusive or, if occlusion occurs, it does so when collateral channels are still adequate. These thrombi then organise into wall plaques, and when further thrombi form, they will do so in similar sites, as the haemodynamic factors responsible for the first thrombus are still operating, and may indeed be exaggerated by the wall disease; thus thrombi and plaques will appear to be related anatomically. When
}

occluding thrombi form in patients whose arterial collateral zone has been reduced by previous thrombotic episodes, cardiac necrosis will occur, and only at this stage will the process, which may have been proceeding steadily for years, declare itself. Although purely hypothetical, this concept is in accordance with the observations. Moreover, there is no evidence for the present view that thrombosis is the result of wall disease, whereas there is good evidence from Rokitansky (1852), Clark et al. (1936) and Duguid (1946) as well as from our survey that wall disease can result in thrombosis. We suggest, therefore, that the adoption of the hypothesis set out above as a basis for future studies, might advance our knowledge more rapidly by focusing attention on the circulating blood, rather than on the vessel wall lesions, which may be the result and not the cause of thrombosis."

It seems, therefore, that changes in the flowing blood may be of prime importance in ischaemic heart disease, and more so than the changes in the arterial wall which have been so extensively studied.

Coagulation Sequence. What evidence exists for changes in the flowing blood in this disease ? Fig. 2 shows a broad outline of the sequence of events that may occur when flowing blood comes into contact with a foreign surface, leading to the formation of fibrin, and various tests of blood coagulation and thrombosis that may reflect these changes.

\section{INVESTIGATION OF THROMBOSIS}

Methods of studying thrombosis have lagged considerably behind those for the study of blood coagulation in relation to the bleeding disorders; four will be considered. These are Wright's (1941) method of studying platelet stickiness, in which the tendency of platelets to stick to glass is studied; platelet turnover using radioactive phosphorus, which measures platelet survival, and has been used

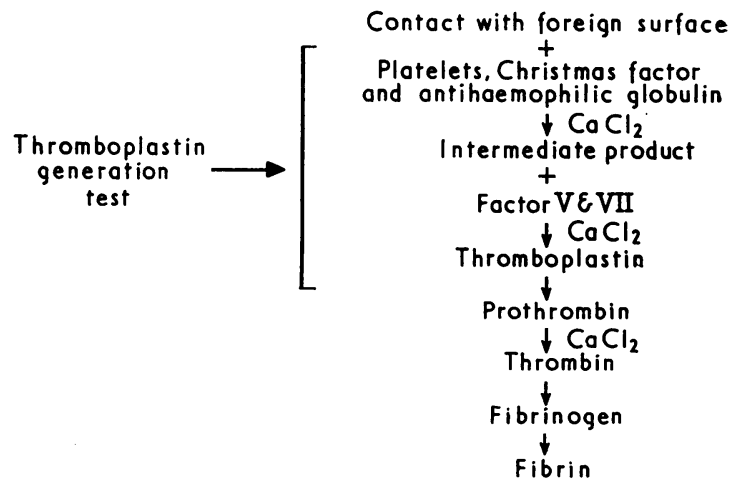

FIG. 2.-Hypothetical scheme of blood coagulation and tests (see text). Modified from Biggs (1955). 
extensively by Mustard (Mustard et al., 1962); Born's (Born and Cross, 1963) method of studying platelet aggregation, which reflects the tendency of platelets to adhere to one another; and Chandler's (1958) method. In the last there is the unusual situation that a structure very like a thrombus is produced in vitro; blood that is circulated in a rotating wheel is observed and the rate of thrombus formation and the microscopical structure of the "thrombus" examined. It differs, however, in at least one important aspect from thrombosis in vivo, in that the arterial endothelium is lacking from the preparation.

In Wright's (1942) original study, platelet stickiness was found to be increased 7 to 10 days after parturition and major operations, at which time it is recognized that intravascular thrombosis is likely to occur. A small amount of blood is placed (Wright, 1941), after a minimal amount of heparin has been added, in a glass bulb (Fig. 3A). This is rotated, usually for a period of 20 minutes, on a wheel (Fig. 3B); our initial work (McDonald and Edgill, 1957) was done on this appratus.

In Born's method of studying platelet aggregation, platelet rich plasma is rapidly stirred by an electromagnet, and is placed between a light source and a photocell. Changes in optical density are recorded on a galvanometer. Fig. $4 \mathrm{~A}$ shows the laboratory apparatus, with the light source, photocell, water bath, and galvanometer. Used in this way, aggregating substances (Born and Cross, 1963) have been found to be adenosine diphosphate (ADP), whose action was noted by Gaarder et al. in 1961, adenosine triphosphate (Mitchell and Sharp, 1964), though this has subsequently been queried by O'Brien (1962) and its action may be due to its breakdown into diphosphate, and 5-hydroxytryptamine, adrenaline, and noradrenaline (Mitchell and Sharp, 1964). Other studies have shown that thrombin (Schmid, Jackson, and Conley, 1962) may have this effect, as well as certain fatty acids (Hoak, Poole, and Robinson, 1963) and collagen (Zucker and Borrelli, 1962). A likely conclusion is that a final common path for all these aggregating substances is adenosine diphosphate (Haslam, 1964).

Furthermore, if adenosine diphosphate accumulation is prevented by the pyruvate kinase and the 2phosphoenol pyruvate system, then the aggregating ability of thrombin and fatty acids is inhibited (Haslam, 1964). In addition, adenosine and related substances have the ability to inhibit adenosine diphosphate-induced aggregation (Born et al., 1965), antiserotonin compounds to inhibit aggregation induced by 5 -hydroxytryptamine, and phentolamine to inhibit that induced by adrenaline and noradrenaline (O'Brien, 1964). The possible importance of

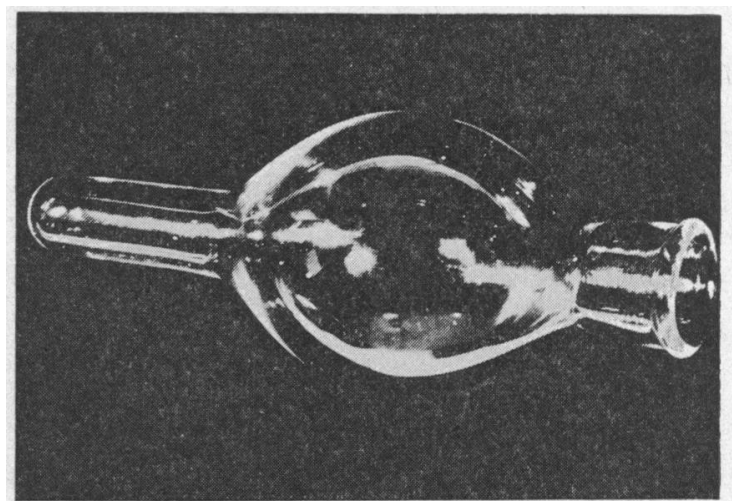

(A)

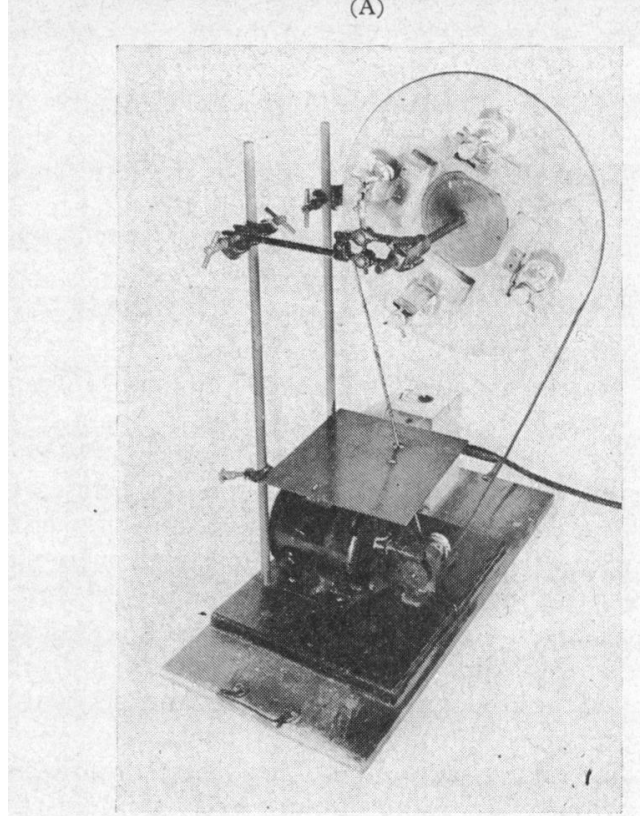

(B)

FIG. 3.-(A) Glass bulb used in platelet stickiness test. (B) Rotating wheel used by Wright (1942) in the estimation of platelet stickiness.

these substances in inhibiting thrombosis will be considered later. Fig. 4B shows normal platelet aggregation using Born's method. Optical density is altered, by the addition of the nucleotides in various concentrations, during the early minutes after the addition of the nucleotide.

Fig. 5 shows the apparatus used in Chandler's (1958) method; a plastic tube containing blood is placed on a rotating wheel. A protractor is fixed to the wheel to measure various parameters, and the whole is driven by an electric motor.

Studies of Platelet Stickiness. In studying mechanisms which may relate to thrombosis, in the blood of patients with ischaemic heart disease and 


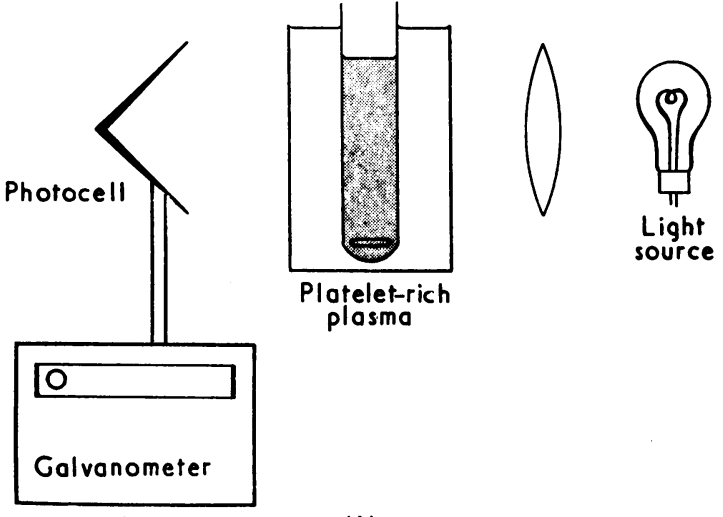

(A)

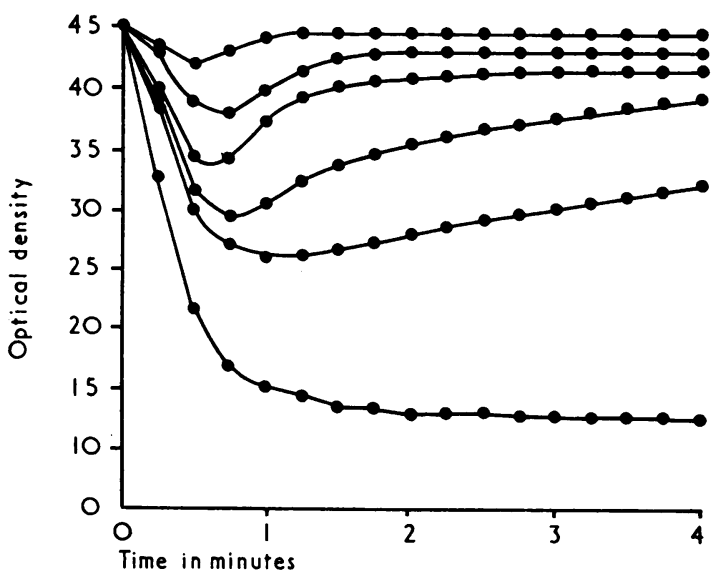

(B)

FIG. 4.-(A) Apparatus used in Born's method of studying platelet aggregation, as described in text. (B) Normal platelet aggregation by Born's method; see text.

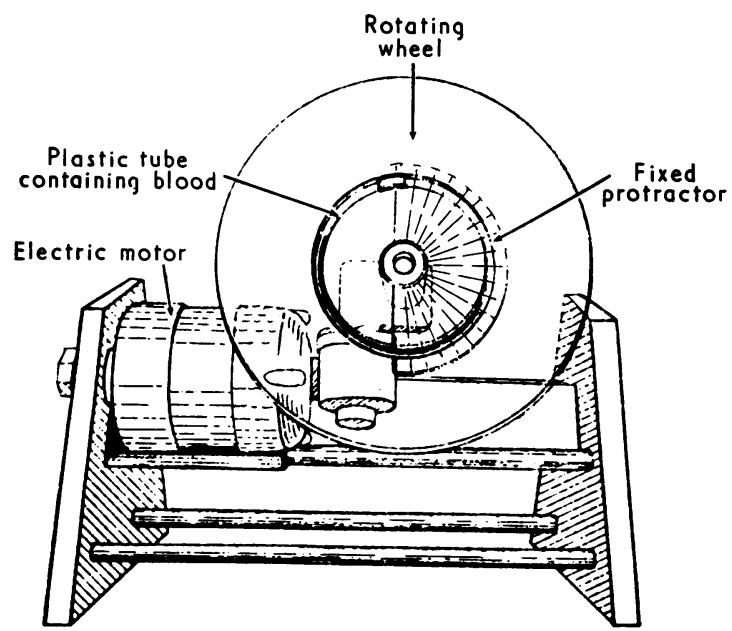

FIG. 5.-Apparatus used in Chandler's method (see text). From Chandler' 1958). apparently healthy controls, the importance of studying patients and controls with these methods cannot be overemphasized, as absolute values are probably less important than the comparison between normality and patients who have the disease. After an initial study (McDonald and Edgill, 1957) between patients with ischaemic heart disease and controls, which showed platelet stickiness, fibrinogen levels, and thromboplastin generation to be significantly increased and which demonstrated hypercoagulability of the blood in the patients, the findings in patients in different stages of the disease and in controls were investigated (McDonald and Edgill, 1959). The different stages of ischaemic heart disease were angina pectoris on exertion, acute coronary insufficiency (Master, Jaffe, and Pordy, 1954), and recent cardiac infarction. Significant differences (at the 0.01 level) were shown between platelet stickiness in controls and patients (Fig. 6), and in comparing those with angina pectoris with those who had a recent cardiac infarction, there was a further significant increase in platelet stickiness. In this respect the patients with acute coronary insufficiency behaved similarly to those with angina pectoris.

One of the two controls with the most abnormal platelet stickiness developed cardiac infarction two years later. Other instances now exist of patients in whom platelet behaviour was abnormal before the development of cardiac infarction. A physician who had a cardiac infarction had repeatedly studied

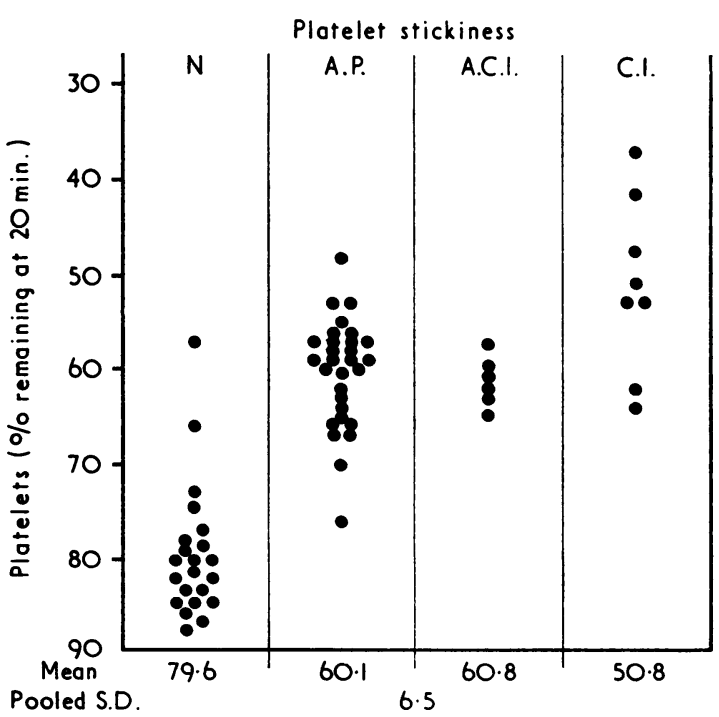

Frg. 6.-Platelet stickiness in ischaemic heart disease (see text). N, normal; A.P., angina pectoris; A.C.I., acute coronary insufficiency; C.I., cardiac infarction. From McDonald and Edgill (1959). 
his own blood platelets over the preceding year, and they were consistently abnormal. It is entirely possible that in population studies abnormal platelet stickiness might not be apparent before cardiac infarction; it seems, from our repeated studies on patients and controls over the years, that the change in the platelets may be of comparatively short duration. Findings on abnormal platelet stickiness in ischaemic heart disease have been confirmed in different countries, particularly by T. R. E. Pilkington (1960, personal communication) and by Nestel (1961).

A similar change in platelet behaviour has been described in patients with recurrent venous thrombosis and pulmonary embolism (Hirsh and McBride, 1965; Thomas, Gurewich, and Ashford, 1966).

Besterman, Myat, and Travadi (1967) have recently confirmed the difference in platelet stickiness between patients and controls (significant at the 0.01 level in their experience), and have shown an interesting and significant diurnal variation in platelet stickiness, with an increase towards the end of the day. Further, they studied the possibility, with experimental evidence, of a link in platelet behaviour and catecholamine excretion.

Evans and Irvine (1966) have made observations on patients with arterial grafts, which lend important weight to the possibility of platelet behaviour being abnormal before the onset of arterial thrombosis. They found that increased platelet stickiness was accompanied by a much reduced likelihood of long-term patency in arterial grafts.

The pattern with regard to fibrinogen levels (McDonald and Edgill, 1957, 1959) was similar to that of platelet stickiness, with a significant increase at the 0.01 level between the controls and the patients, and the difference between the patients and controls was most marked after recent cardiac infarction. A similar pattern existed in thromboplastin generation with the same significant difference.

Causes of Abnormal Platelet Stickiness. As a result of preliminary investigations the behaviour of the blood platelets in ischaemic heart disease seemed to merit further study; and, of prime importance was the question as to what was the cause of abnormal platelet stickiness. Accordingly, levels of the enzyme lipoprotein lipase were determined in patients with ischaemic heart disease and in normal men who acted as controls, and were related to platelet behaviour (Slack et al., 1964) (Fig. 7). Lipoprotein lipase activity was significantly lower $(p<0.001)$ in the men with ischaemic heart disease than in the normal subjects, and the difference between the activity of the enzyme in all men with an affected first-degree relative and all men with no affected first-degree relative was similarly significant.

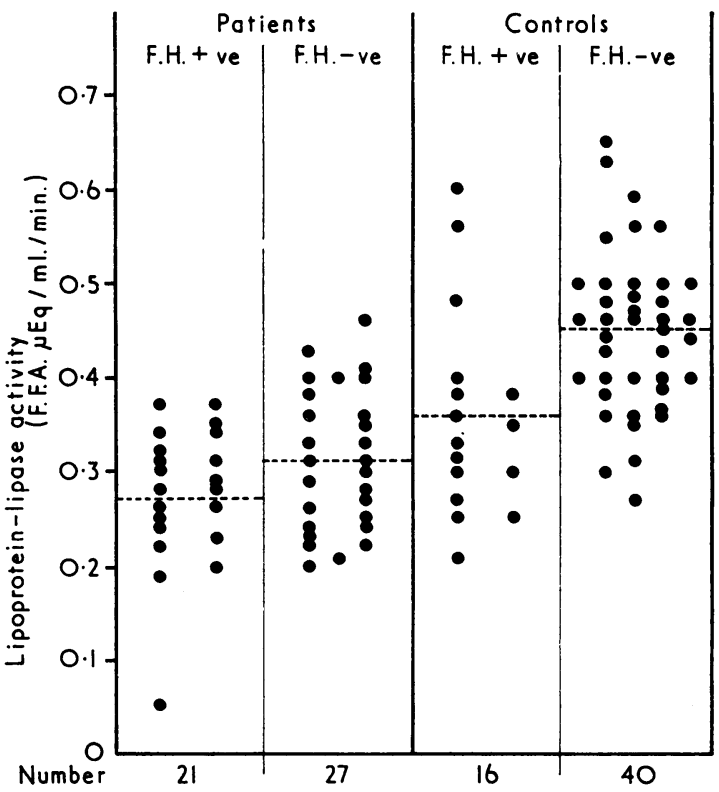

FIG. 7.-Lipoprotein lipase activity in men with ischaemic heart disease and in normal men, distinguishing those who have a first-degree relative with the condition. F.H.+ve, affected first-degree relative verified; F.H. - ve, no affected first-degree relative verified. From Slack et al. (1964).

Further, the mean level of lipoprotein lipase activity in the controls with an affected first-degree relative was nearer to the mean level of all the patients, than to the controls with no affected first-degree relative. Thus, it was apparent that lipoprotein lipase might be concerned in the aetiology of ischaemic heart disease, and the presence of a genetic factor in the enzyme deficiency seemed likely. When platelet stickiness and lipoprotein lipase were compared in the controls (Fig. 8) there was a highly significant correlation between platelet stickiness and lipoprotein lipase in the controls $(p<0.001)$. A less significant correlation existed between platelet stickiness and lipoprotein lipase in the patients with ischaemic heart disease.

Thus, a correlation was shown between decreasing lipoprotein lipase activity and increasing stickiness of the blood platelets, which was more significant in the normal men than in the men with ischaemic heart disease. Since patients with ischaemic heart disease have increased platelet stickiness and diminished lipoprotein lipase activity, any correlation between these in the patients may be fortuitous. In normal men, however, the significance of the relation between lipoprotein lipase activity and platelet stickiness is real, since the common factor of overt ischaemic heart disease is lacking. 


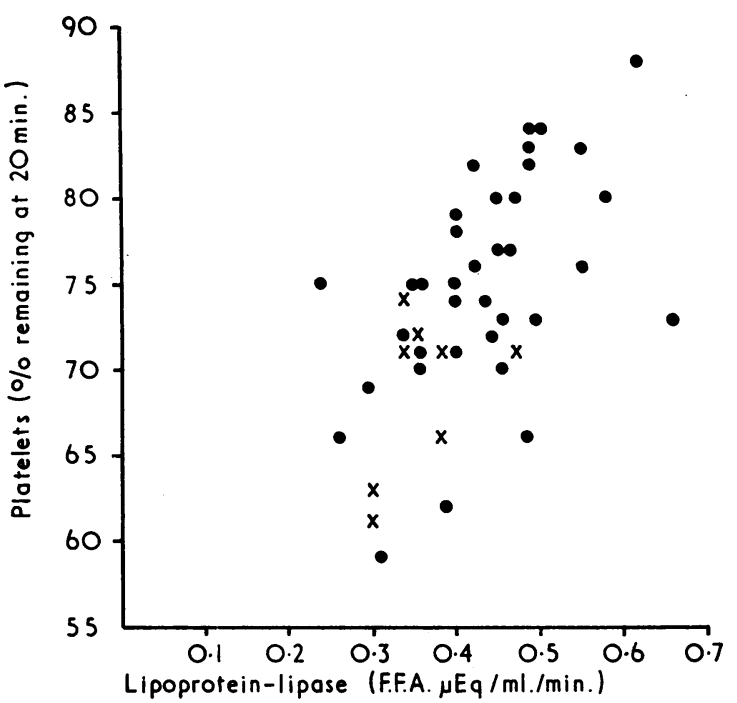

FIG. 8.-Platelet stickiness and lipoprotein lipase activity in normals (no. $=43, r=0.593, p<0.001$ ). $\bullet$, no affected firstdegree relative; $x$, affected first-degree relative. From Slack et al. (1964).

A study of homocystinuria (McDonald et al., 1964) is relevant to ischaemic heart disease. In homocystinuria there appears to be a metabolic block in the chain of events, methionine $\rightarrow$ homocystine $\rightarrow$ cystathione, and subsequently the levels of plasma and urinary homocystine are raised. The disease is characterized by arterial and venous thromboses in childhood and early life. These children present with various somatic abnormalities and with mental defect. Because of their precocious intravascular thrombosis, it seemed worth while to study their platelet stickiness, and it was found to be greatly increased in these children as compared to normal healthy children (Fig. 9), and when homocystine was added in physiological concentrations to normal heparinized blood it resulted in greatly enhanced platelet stickiness (Fig. 10) (Bray and McDonald, 1964). Thus, a natural experiment was presented, i.e. a disease with a welldefined metabolic background, in which platelet stickiness could be identified with, and attributed to, an abnormal biochemical constituent in the blood.

Abnormalities of Platelet Turnover. Mustard and his colleagues, using radioactive phosphorus to determine platelet turnover and survival in ischaemic heart disease, have shown that platelet turnover is abnormal in ischaemic heart disease (Murphy and Mustard, 1962), and that this change is adversely affected by a diet that is rich in fat and eggs (Mustard and Murphy, 1962), by fatty acids (Murphy et al.,

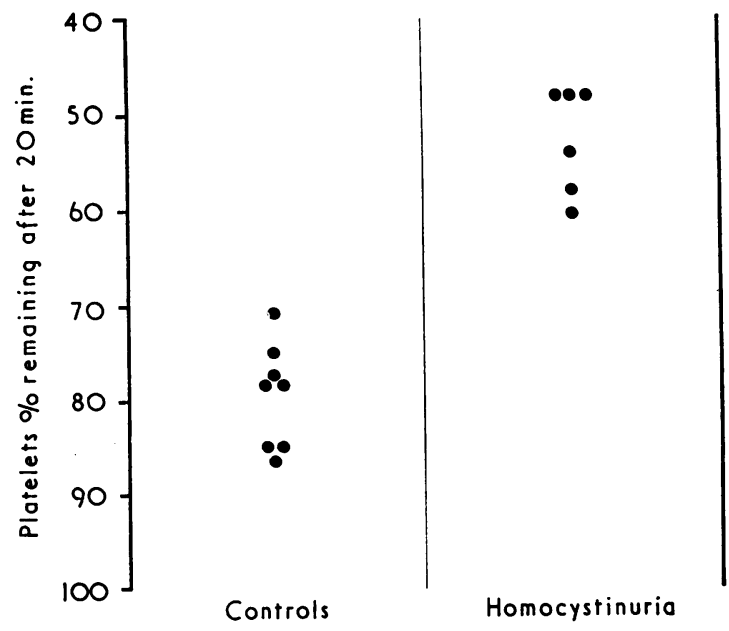

FIG. 9.-Increased platelet stickiness in homocystinuria (see text).

1963), and by cigarette smoking (Mustard and Murphy, 1963a), while heparin may produce a favourable effect (Mustard and Murphy, 1963b). In animal experiments, Mustard (Mustard et al., 1962) stressed the importance of the mechanical factor in vessel-wall thrombosis, which seems likely also to be important in people with ischaemic heart disease.

Chandler's Method. This has been used in ischaemic heart disease. Ardlie, Kinlough, and Schwartz (1966) found a tendency to abnormal in

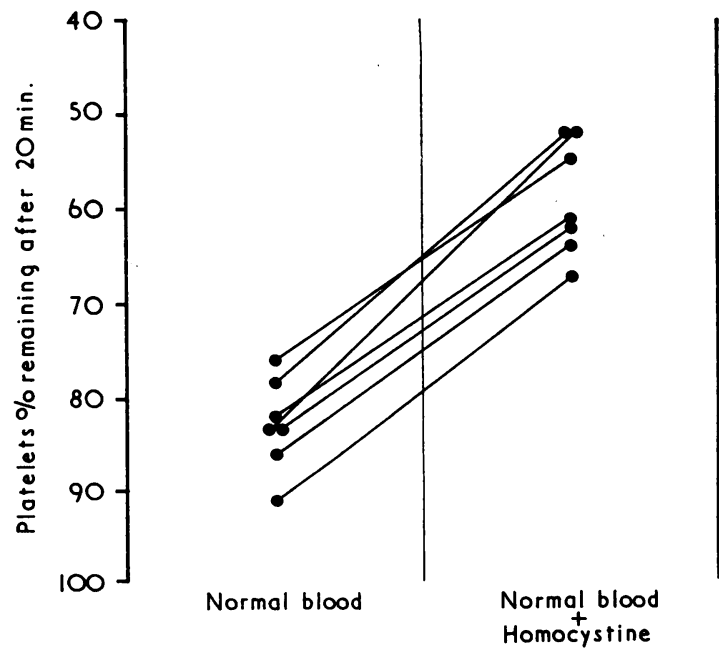

FIG. 10.-Effect of homocystine, added to normal heparinized $(5 \mathrm{u} . / \mathrm{ml}$.) blood in physiological concentrations, on platelet stickiness (see text). 
vitro thrombosis and platelet aggregation in cardiac infarction, and a decrease in the time for thrombus formation with cigarette smoking has been claimed by Engelberg (1965), who suggested that this action was through the nicotine-induced release of adrenaline.

Platelet Aggregation in Ischaemic Heart Disease. Platelet aggregation, using Born's method, has been used to investigate a number of patients over the past two years (Bray, McDonald, and Davies, 1967a). Fig. 11 shows the usual response in controls and in some patients; with the increasing doses of nucleotide the platelets aggregate together and disaggregate. There has been a tendency in the patients for higher peaks of aggregation than in the controls. Moreover, in some controls and in more patients, there was a phenomenon that we have termed "secondary platelet aggregation" (Bray and McDonald, 1966). Fig. 12 shows an example; with intermediate doses of adenosine diphosphate the platelets aggregate together, and then, instead of spontaneously disaggregating, there is a phenomenon that may be termed "secondary aggregation", as shown on the middle curve $A$. In these subjects the platelets spontaneously aggregate again to form massive platelet clumps. These patients may well represent some in whom the thrombotic tendency is particularly prominent. Evidence now exists (C. Bray and L. McDonald, 1967, unpublished data) that there is a seasonal variation in aggregation both in the patients and in the controls, though at each period of the year the patients seem more sensitive in the response to adenosine diphosphate.

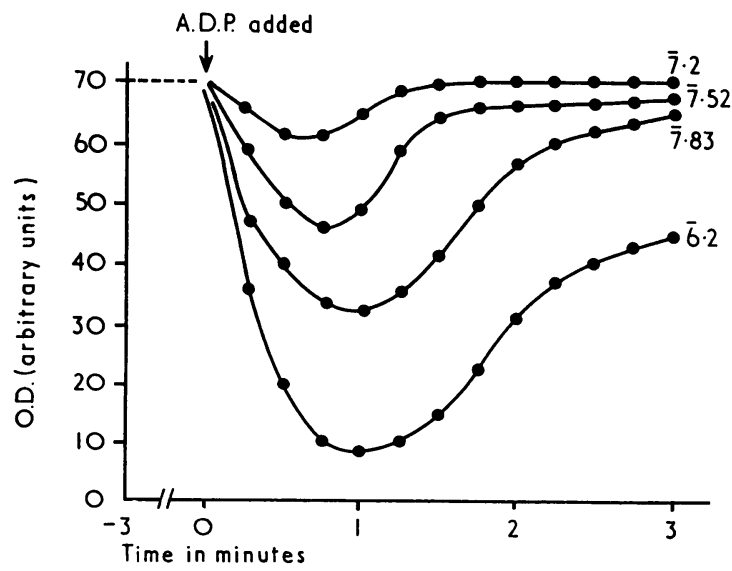

FIG. 11.-Normal aggregation and disaggregation using Born's method (see text). O.D., optical density; A.D.P., adenosine diphosphate.

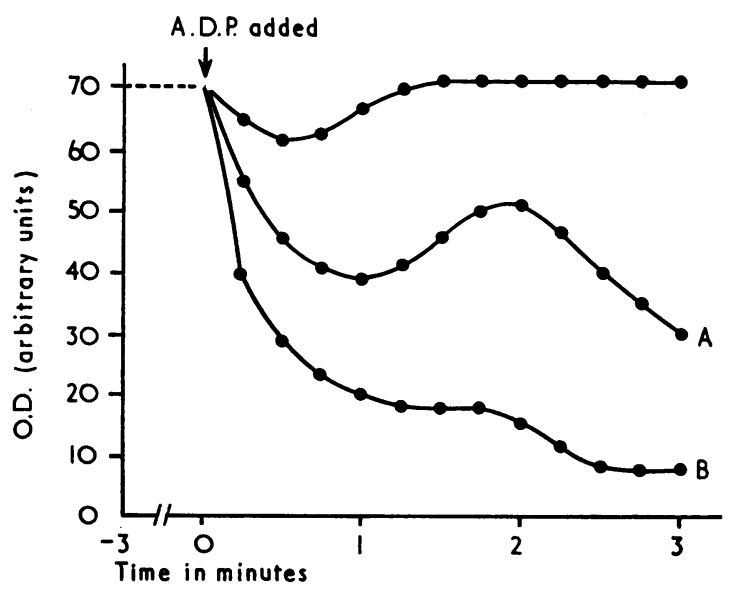

FIG. 12.-Secondary aggregation, using Born's method (see text). O.D., optical density; A.D.P., adenosine diphosphate.

An abnormal biochemical background has been shown to be associated with abnormal platelet behaviour, though not as yet in every instance in direct relation to ischaemic heart disease, and this must be further considered.

Adenosine Diphosphate (ADP). Born (1962) demonstrated that adenosine diphosphate was contained in the surface membrane of the blood platelet. Emmons et al. (1965a, b) showed that ADP-induced aggregation of the platelets is inhibited by dipyridamole, with a therapeutic possibility that will be considered later. Furthermore, Hampton and Mitchell (1966) have shown that ADP appears to alter the surface charge of platelets, and this is shown in a change in their electrokinetic response. After the addition of ADP, Seaman et al. (1967) have observed platelet microemboli in the living extracorporeal bovine eye, and Mustard et al. (1964) have noted platelet thromboses in the small coronary vessels of swine. Zucker and Borrelli (1962) have shown the effect of collagen in causing platelet clumping, and Schmid et al. (1962) have described the effect of thrombin.

Clayton and Cross (1963) considered that the aggregation of platelets, whether induced by ADP, thrombin, or catecholamines, occurred through some final common path which is blocked by adenosine, and which therefore probably always involves ADP. Hampton and Mitchell (1966) have produced evidence of a transferable factor causing abnormal platelet behaviour in vascular disease, finding a characteristic pattern of platelet electrokinetic behaviour in ischaemic heart disease, peripheral occlusive arterial disease, hypercholesterolaemia, 
diabetes mellitus, and homocystinuria. This amounted to an undue sensitivity to adenosine diphosphate, and a normal reaction to noradrenaline. The nature of this factor is not yet known. In human studies, Bygdeman, Eliasson, and Johnson (1966) have shown an increased sensitivity of the platelets to adenosine diphosphate after operations.

It seems probable that abnormal platelets are acting as an indicator system for a factor that is released from other blood cells during the preparation of platelet-rich plasma.

\section{Carbohydrate Metabolism in Ischaemic Heart DISEASE}

Yudkin (1964) suggested that the dietary intake of sugar, which closely parallels that of fat intake, might be of vital importance in the genesis of the disease. Fig. 13 shows his findings with regard to the fat and sugar intake in 41 countries. He considered that statistics relating to the fat intake in ischaemic heart disease, or diabetes mellitus, in different populations, may therefore express only an indirect relation and that the causal relation may be with sugar.

With regard to carbohydrate metabolism in ischaemic heart disease, numerous studies including those of Cohen and Shafrir (1965) have shown that glucose tolerance is abnormal in patients with ischaemic heart disease, which may be of interest in relation to Yudkin's (1964) findings. High levels of plasma insulin in ischaemic heart disease have been recorded by Peters and Hales (1965) and by Nikkilä

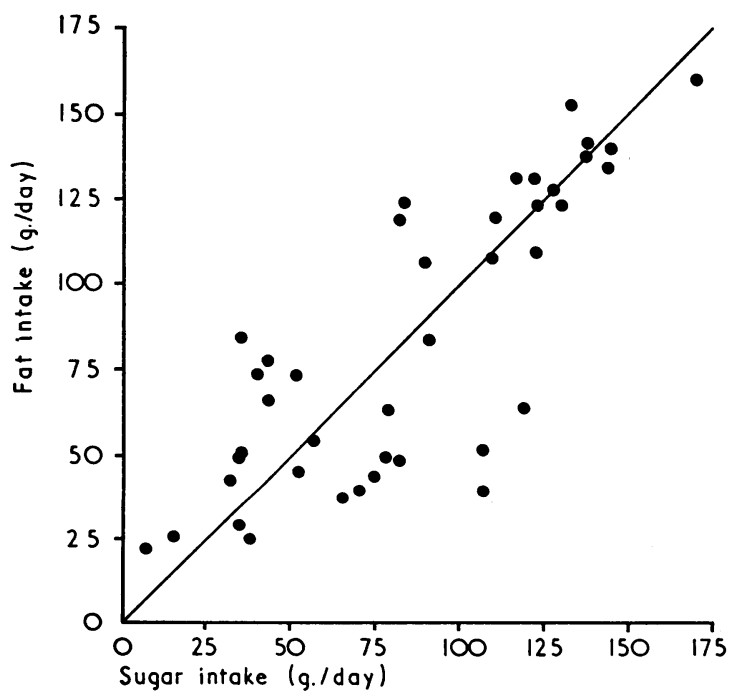

Fig. 13.-Relation between average fat intake and sugar intake in 41 countries (see text). From Yudkin (1964). et al. (1965), and increased insulin antagonism by Vallance-Owen and Ashton (1963). Keen et al. (1965) have produced evidence that changes in glucose tolerance may precede the clinical development of ischaemic heart disease. Bridges et al. (1965) found increased platelet stickiness in diabetic patients, which was enhanced by added glucose. The viscosity of the blood is also increased in diabetic patients (Skovborg et al., 1966). Ostrander and Weinstein (1964) have demonstrated electrocardiographic changes involving the $S-T$ segments and $T$ waves after glucose ingestion, which were more frequent in patients with coronary heart disease than in apparently normal men.

\section{FatTy ACIDS AND Thrombosis}

The relationship of the fatty acids may be important in thrombosis and in ischaemic heart disease. Soloff and Schwartz (1966) found that the fatty acid response to a glucose load was increased in ischaemic heart disease. Poole, Connor, and their colleagues (Connor and Poole, 1961; Connor, Hoak, and Warner, 1963; Poole, 1955) have shown that the long chain saturated fatty acids may enhance thrombosis, and that rapid lipid mobilization, leading to a high free fatty acid concentration, can result in thrombosis (Hoak et al., 1963). Dole (1956) demonstrated an increase in fatty acids in the blood after adrenaline. The effects of fatty acids on blood coagulation and thrombosis have been studied by Connor, Hoak, and Warner (1965). The results obtained from tests of the effects of various saturated fatty acids on the blood from 13 subjects are shown in Fig. 14. The control thrombus formation time, with sodium chloride, averaged $8 \cdot 3$ minutes. Short chain fatty acids of chain length $\mathrm{C} 6-\mathrm{C} 10$ did not significantly accelerate thrombus formation time, but there was progressive shortening of the thrombus formation time as the chain length of the fatty acid increased from $\mathrm{C} 10$ onwards: $\mathrm{C} 14$ produced a

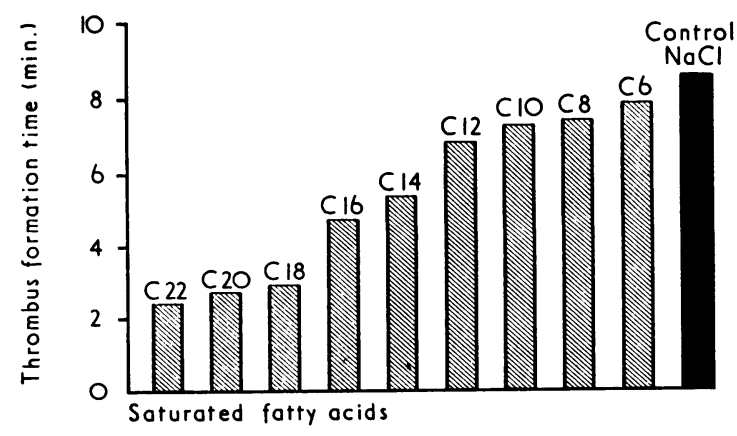

Fig. 14.-Effects of various saturated fatty acids on thrombus formation (see text). From Connor et al. (1965). 
time of 5.3 minutes, palmitic, or C16, a time of 4.8 minutes; C18, C20, and C22 had especially great accelerating effects, with thrombus formation times as low as $2 \cdot 4$ minutes.

\section{Fibrinolysis AND Thrombosis}

Fibrinolysis and thrombolysis may be of extreme importance in ischaemic heart disease, but our own findings (Katz et al., 1963), and those of others, which have been summarized by Fearnley (1965), remain inconclusive. This may well be because of the still indifferent methods of examining these mechanisms. However, Ogston and Fullerton (1965) consider that fibrinolysis may be particularly active 5 to 8 hours after cardiac infarction, and that 8 to 10 days later there is no significant difference between the findings in patients and controls. Warren (1964) has suggested that the vascular endothelium releases plasminogen activator, with the rapid dissolution of thrombi on intact endothelium. Fearnley (1965), in reviewing the subject, concluded that fibrinolysis and platelet behaviour might not be unrelated.

\section{RHEOLOGY}

The study of rheology in ischaemic heart disease awaits development. Three microrheological mechanisms in thrombogenesis appear to be important; these are the aggregation of red cells, the agglutination of platelets under a velocity gradient, and an increase in the internal rigidity of the red cells as a function of the $p \mathrm{H}$ (Dintenfass, 1965). Increased viscosity after cardiac infarction has been described by Dintenfass (1964) and by Mayer (1964).

\section{Haematocrit and Red Cells}

Increased haematocrit values with erythrocytosis have been reported in ischaemic heart disease by Burch and DePasquale (1962), though this has been denied by Conley et al. (1964). The liberation of material with platelet-like coagulant properties from the red cells, which could accelerate thrombosis, has been shown by Bradlow (1961). Harrison and Mitchell (1966), in studying the influences of red cells on platelet adhesiveness, found evidence that abnormal platelet stickiness might be related to red cell abnormalities, by the liberation of ADP from mechanically damaged erythrocytes.

\section{Biochemical CoRrelations}

Possible correlations between the platelet abnormalities and the biochemical abnormalities, that have been described in ischaemic heart disease, have recently been studied (Bray et al., 1967b). Relevant parameters in 60 patients with ischaemic heart disease and 60 controls have been investigated, and were usually adverse, to a significant degree, in the patients. These included platelet count, stickiness, and aggregation, haematocrit, free fatty acids, glucose tolerance, plasma insulin, lipoprotein lipase, plasma triglycerides, serum cholesterol, and serum uric acid. Preliminary analysis showed that carbohydrate intolerance in the patients was significantly correlated with some aspects of the ADP reaction. Plasma cholesterol correlated with the platelet count, which is itself significantly higher in some patients with ischaemic heart disease (McDonald and Edgill, 1959). The red cells also appeared to be significantly related to some aspects of the ADP reaction, which was declared in the relation between the packed cell volume and the ADP reaction in the patients.

\section{IN VIVO STUDIES}

It is obviously important to compare these in vitro studies with what is known of relevant platelet behaviour in vivo. Do platelets aggregate or stick together in vivo? Considerable work has been done on various animal preparations and this suggests that they do. In man the information is obviously more difficult to obtain. Fig. 15, an etectron-microscopical photograph taken by Dr. John French (French, MacFarlane, and Sanders, 1964), shows part of the wall of a small vein in a hamster cheek pouch. The vein was not deliberately injured, but it was near to an injured artery and had probably been damaged during manipulation of the pouch. A platelet occupies a gap in the endothelium at an intercellular junction, and other platelets in the lumen are clearly seen to be sticking to it. This elegant study is in full agreement with the early work of Eberth and Schimmelbusch (1886) and Bizzozero (1882), who recognized the important role that platelets played in the initiation of thrombosis.

In the coronary arteries of man it is understandably difficult to study in vivo the phenomena of platelet aggregation and platelet stickiness. But photographs of the ocular fundus that were obtained by Dr. Ross Russell (Ross Russell, 1961) in a case of monocular blindness may be analogous to similar events occurring in the coronary arterial tree. Fig. 16 shows an aggregation of platelets, the so-called white body, passing through a fundal arteriole. This was accompanied by transient blindness in the patient, and it might be considered that such temporary occlusion may have its counterpart in some patients with ischaemic heart disease and transient episodes of cardiac pain at rest. Some 10 to 15 minutes later a photograph of the same fundus shows the passage from the arteriole of the platelet 


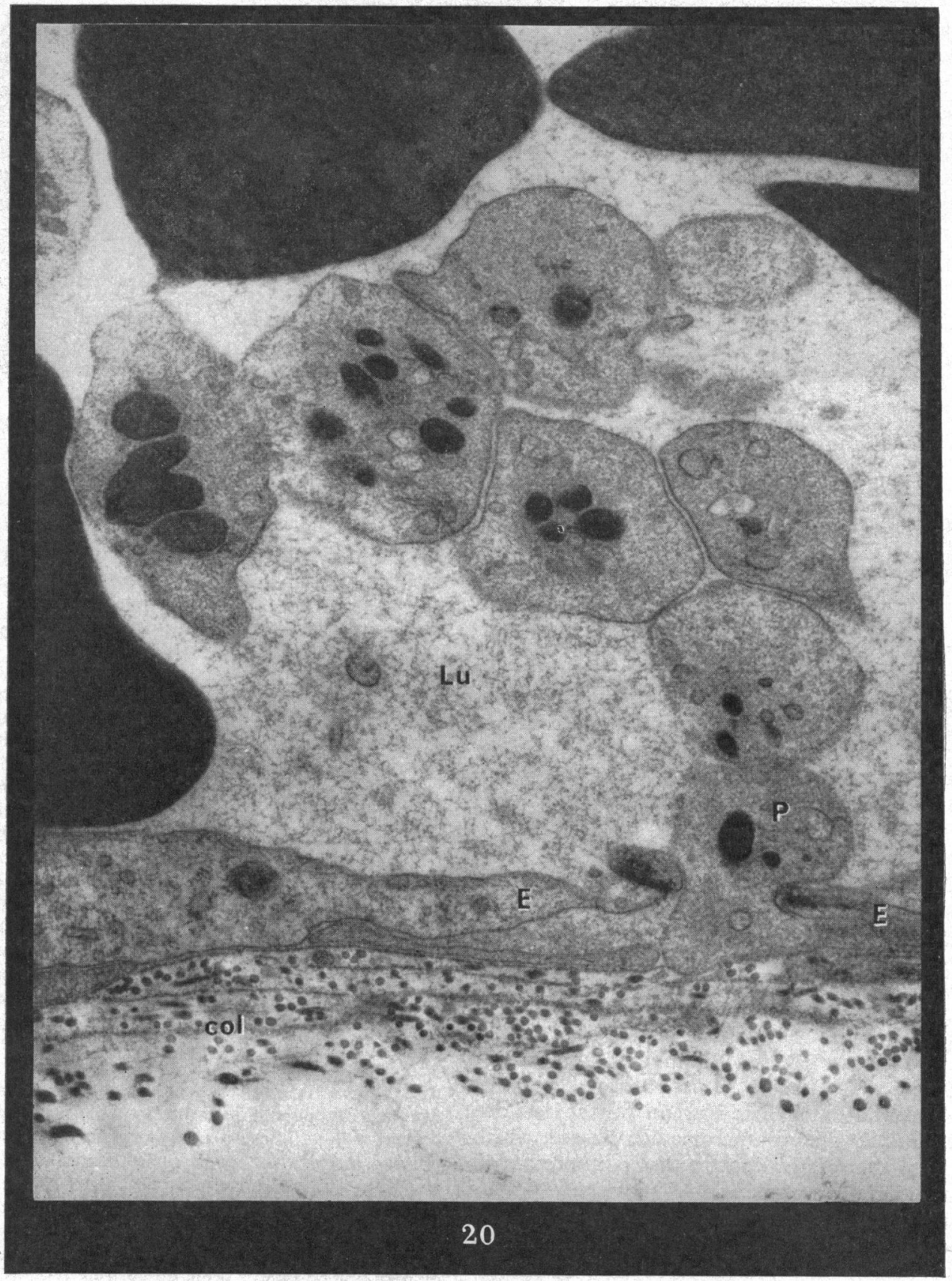

FIG. 15.-Electron-microscopical photograph of a small vein in the hamster cheek pouch. A platelet (P) occupies a gap in the endothelium (E) at an intercellular junction. Other platelets in the lumen (Lu) are adherent to it (see text). From French et al. (1964). 


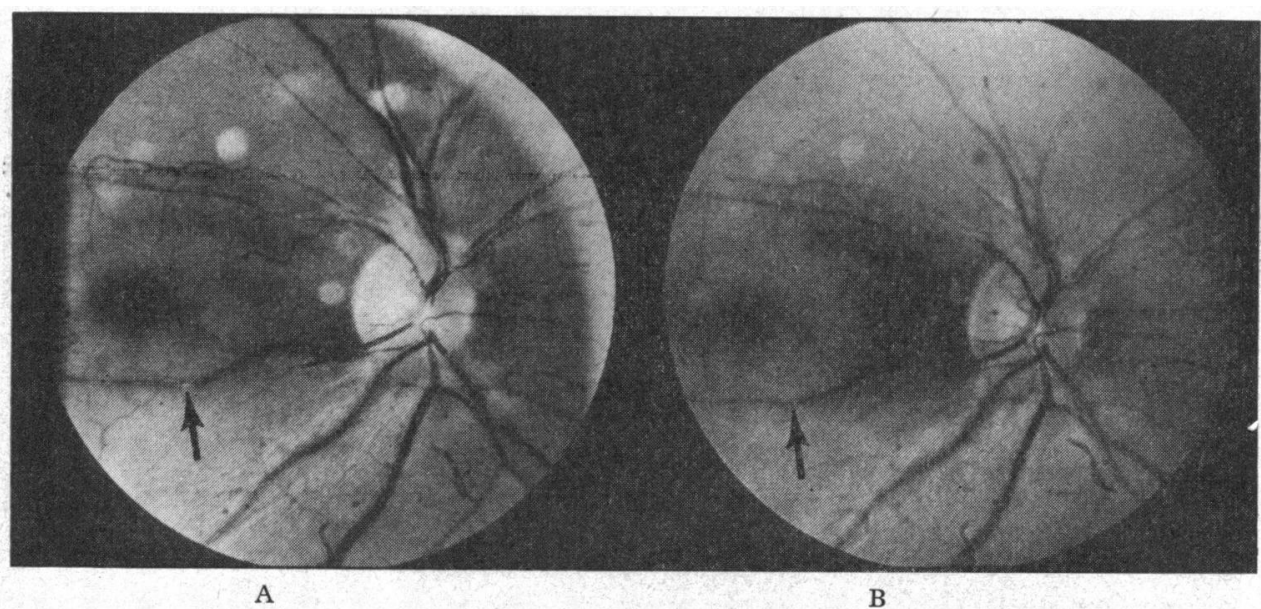

FIG. 16.-Retinal photographs showing the passage of a white body through a fundal arteriole with an interval of 10-15 minutes between photographs (A) and (B). (By courtesy of Dr. R. W. Ross Russell).

white body, and at the time the patient's vision was unimpaired.

Therefore, there is now abundant evidence of important changes in the circulating blood in patients after cardiac infarction. The question as to whether these changes occur before infarction, or subsequent to it, remains important, and it is easy to appreciate the difficulty in obtaining this information. But already there is considerable evidence that the circulating blood is abnormal in these patients before cardiac infarction occurs, in a way that is likely to predispose to thrombosis.

\section{Why the Coronary ARTERIES ?}

In the above respect it is often asked why it is that the coronary arteries thrombose and not arteries all over the body. However, patients with ischaemic heart disease have an abnormally high incidence of peripheral occlusive arterial disease (McDonald, 1953); thus more generalized arterial thrombosis is frequent in them. However, there are good reasons why, in a person liable to thrombose, the coronary arteries are so frequently the site of thrombosis. In the coronary arteries there is frequently at least one small critically placed atheromatous plaque, which may form the foreign contact that is important in the initiation of thrombosis. Otherwise the coronary arteries differ from others throughout the body in that their flow, in a major part of the coronary system, appears to occur in diastole as opposed to systole, and it is very likely that the flow is turbulent as opposed to laminar, which may enhance the tendency to thrombosis.

Evidence has been presented that the circulating blood is abnormal in patients with ischaemic heart disease, and particularly the blood platelets, and that metabolic reasons may account for these changes. Facts are accumulating to indicate that the abnormalities, which have been described, occur before the disease is clinically manifest. Sir George Pickering (1965) has put the situation in good perspective.

"The immediate cause of infarction of the heart is in most cases, though possibly not in all, a thrombus occluding a branch of a coronary artery, particularly the left anterior descending. The thrombus has a characterising structure-clumps of platelets fringed with leucocytes and interlaced with a fibrin meshwork which often contains red cells or the ghosts of red cells. As the thrombus ages the nuclei disappear, and it becomes more uniform in composition. Later it becomes organised and recanalised. The longer the interval between the clinical attack and death, the less likely is there to be a fresh thrombus and the more likely is there to be a characteristic plaque of intimal thickening producing coronary stenosis. A unitary view would imply that most stenosing plaques in coronary arteries represent the remnants of past thrombi of similar composition.

A working hypothesis of the nature of this disease is thus that it is a disease in which leucocyte-plateletfibrin thrombi occur episodically in arteries, especially at certain sites. These become organised and are incorporated into the intima as raised plaques. The media atrophies and the adventitia becomes vascular and infiltrated with cells. In this stage the disease is symptomless. Eventually a thrombus occludes a coronary artery, and the well-known syndrome occurs which may or may not be fatal. This hypothesis resembles that of Rokitansky and Duguid, but differs in stressing that arterial thrombi contain platelets and leucocytes as well as fibrin. This is no more than a working hypothesis, but is as well substantiated as any other. If it is correct then the platelets would seem to occupy a key position." 

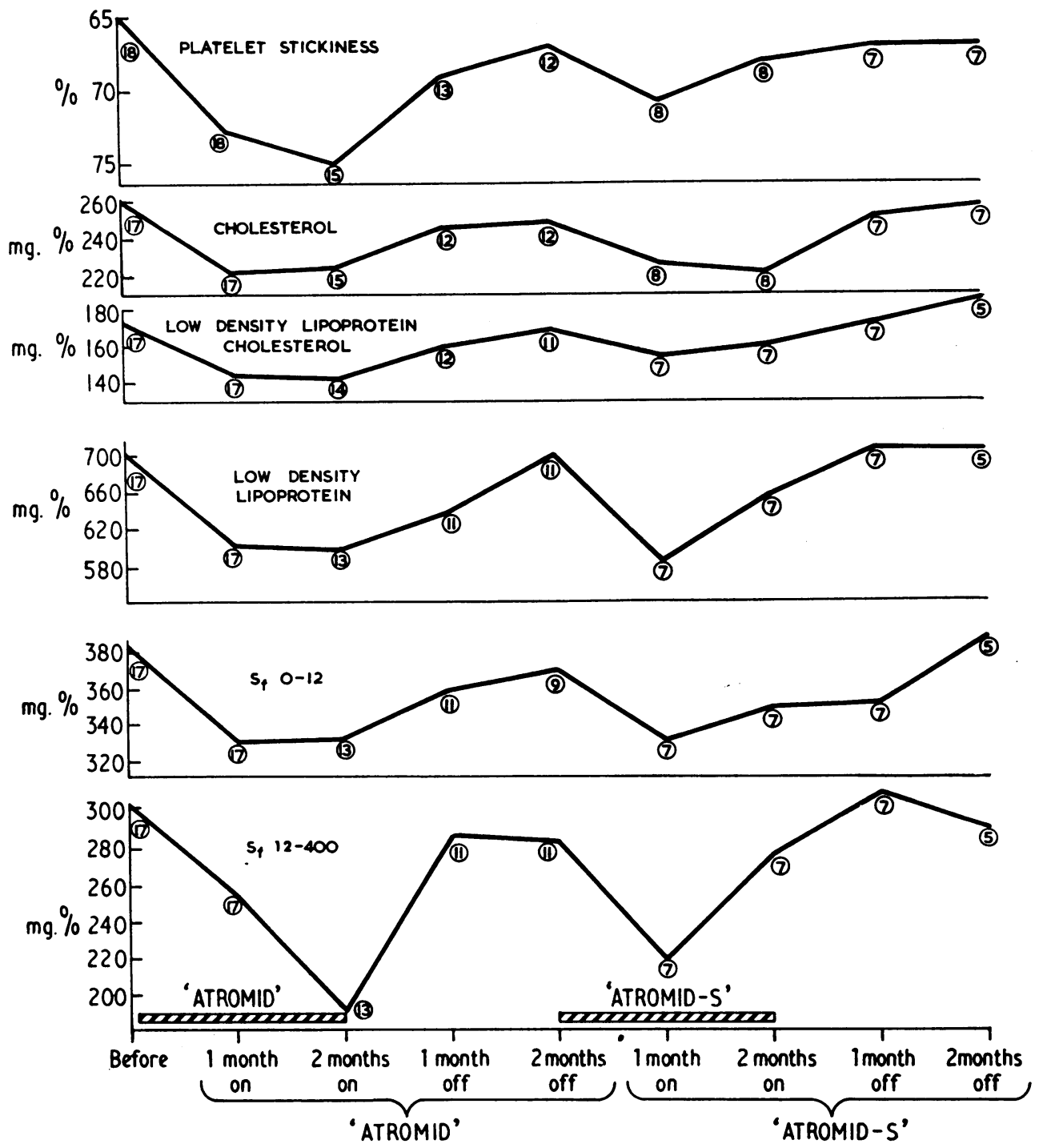

Figures in circles indicate number of patients tested

Fig. 17.-Mean values for platelet stickiness (\% remaining at 20 minutes), cholesterol, low density lipoprotein cholesterol, low density lipoprotein, Sf 0-12 lipoprotein, and Sf 12-400 lipoprotein in patients receiving atromid and atromid-S. From Carson et al. (1966).

\section{ANTicoagulant Therapy}

For clinicians not only the genesis of a disease but its management is important. What information exists regarding present and future therapy for the control of thrombosis in ischaemic heart disease ? Every clinical cardiologist is aware of the disappointing results of so-called anticoagulant treatment; we have shown that existing tests reveal the inadequacy of anticoagulant treatment to control a thrombotic tendency (McDonald, 1962).

Potentially Antithrombotic Measures. Aware of these disappointing therapeutic measures, various manoeuvres have been studied which may favourably alter platelet behaviour in these patients. After the rice-fruit diet a number of patients with ischaemic heart disease showed a significant reduction in 
TABLE III

EFFECT OF RICE-FRUIT DIET ON PLATELET STICKINESS AND SERUM CHOLESTEROL (FROM MCDONALD AND EDGILL, 1958)

\begin{tabular}{l|c|c}
\hline & $\begin{array}{c}\text { Platelet stickiness } \\
(\% \text { initial count } \\
\text { at 20 min. })\end{array}$ & $\begin{array}{c}\text { Serum cholesterol } \\
(\mathrm{mg} / 100 \mathrm{ml})\end{array}$ \\
\hline Non-diet patients & $\begin{array}{c}60 \cdot 0^{\star} \\
(\mathrm{SE} 1 \cdot 6)\end{array}$ & $\begin{array}{c}290^{\star} \\
(\mathrm{SE} \mathrm{7}) \\
21 \cdot 8^{\star}\end{array}$ \\
\hline Diet patients & $215^{\star}$ \\
\hline
\end{tabular}

$\star$ Significant at $0 \cdot 1$ per cent levels.

platelet stickiness, together with total serum cholesterol (Table III) (McDonald and Edgill, 1958). The findings were highly significant both in the reduction of platelet stickiness and cholesterol, though the two changes appeared to be independent of one another. In this connexion, Geill, Hansen, and Lund (1960) found a reduction in thrombosis and embolism in a group of hospital patients having vegetable oils in their diet compared with others. Thus, dietary restriction may yet play an important part in the control of thrombosis.

An interesting drug is the androsterone compound atromid (Thorp, 1962) which contains androsterone and ethyl p-chlorophenoxy isobutyrate. Atromid-S contains only ethyl p-chlorophenoxy isobutyrate, and no androsterone. Fig. 17 shows the changes in platelet stickiness, serum cholesterol, low density lipoprotein cholesterol, low density lipoprotein, Sf fractions $0-12$ and $12-400$ after atromid and atromid-S (Carson et al., 1966). With both atromid and atromid-S there was a significant reduction in platelet stickiness, which was slightly more marked with atromid than with atromid-S.

In considering potentially antithrombotic measures phenindione indifferently affects abnormal platelet behaviour (L. McDonald and F. Love, 1964, unpublished observations), and heparin (McDonald and Edgill, 1961) has the great disadvantage of the need for parenteral administration. Diet may well prove to be important, and possibly even exercise. Ethyl p-chlorophenoxy isobutyrate is a compound that demands further study. And obviously any of these measures that appear worth while demand adequate trials, to determine whether the laboratory changes are accompanied by a reduction in the morbidity and mortality of ischaemic heart disease. Dipyridamole, or persantin, has been shown to affect platelet aggregation favourably (Emmons et al., 1965a) and may be used clinically. Other drugs that may be considered as potentially antithrombotic are adenosine (Born and Cross, 1963; Clayton, Born, and Cross, 1963), the antiserotonins, and phentolamine. However, it seems likely that existing compounds may well not be the final answer, but that current methods of study offer exciting new ways of finding a therapeutic answer to the prevention and treatment of coronary arterial thrombosis.

\section{CoNCLUSIONS}

Thrombosis seems likely to be the final common path of a number of different aetiological factors, in the majority of patients with coronary heart disease.

The tendency to intravascular thrombosis, or its presence, is reflected by abnormal platelet behaviour, which seems likely to be an indicator of other abnormalities in the blood. In this, evidence is mounting that the role, particularly of the catecholamines, free fatty acids, and the red blood cells, may be of considerable importance.

Studies support but do not yet completely prove that disease of the arterial walls is associated with platelet changes and thrombus formation.

The predictive value of platelet changes in the development of ischaemic heart disease merits further study.

The correction of platelet abnormalities in ischaemic heart disease, by diet or by drugs, opens up new possibilities for antithrombotic as opposed to anticoagulant measures, both in the prophylaxis and in the management of the disease.

The author gratefully acknowledges the help of many registrars and research assistants who have taken part in this work and made it possible.

\section{REFERENCES}

Allbutt, C. (1915). Diseases of the Arteries, Including Angina Pectoris, Vols. 1 and 2. Macmillan, London.

Antonis, A., and Bersohn, I. (1960). Serum-triglyceride levels in South African Europeans and Bantu and in ischaemic heart-disease. Lancet, 1, 998.

Ardlie, N. G., Kinlough, R. L., and Schwartz, C. J. (1966). In vitro thrombosis and platelet aggregation in myocardial infarction. Brit. med. F., 1, 888.

Barnes, A. R., and Ball, R. G. (1932). The incidence and situation of myocardial infarction in one thousand consecutive postmortem examinations. Amer. F. med. Sci., 183, 215.

Besterman, E., Myat, G., and Travadi, V. (1967). Diurnal variations of platelet stickiness compared with effects produced by adrenaline. Brit. med. F., 1, 597.

Biggs, R. (1955). Assessment of clotting efficiency. Brit. med. Bull., 11, 5.

Biörck, G., Boström, H., and Widström, A. (1965). On the relationship between water hardness and death rate in cardiovascular diseases. Acta med. scand., 178, 239.

Bizzozero, J. (1882). Ueber einen neunen Formbestandtheil des Blutes und dessen Rolle bei der Thrombose und der Blutgerinnung. Arch. path. Anat. Physiol. Virchow's, 90, 261.

Blumgart, H. L., Schlesinger, M. J., and Davis, D. (1940). Studies on the relation of clinical manifestations of angina pectoris, coronary thrombosis, and myocardial 
infarction to pathologic findings with particular reference to significance of the collateral circulation. Amer. Heart f., 19, 1.

Born, G. V. R. (1962). Aggregation of blood platelets by adenosine diphosphate and its reversal. Nature (Lond.), $194,927$.

and Cross, M. J. (1963). The aggregation of blood platelets. F. Physiol. (Lond.), 168, 178.

-, Haslam, R. J., Goldman, M., and Lowe, R. D. (1965). Comparative effectiveness of adenosine analogues as inhibitors of blood-platelet aggregation and as vasodilators in man. Nature (Lond.), 205, 678.

Bradlow, B. A. (1961). Liberation of material with plateletlike coagulant properties from intact red cells and particularly from reticulocytes. Brit. F. Haemat., 7, 476.

Bray, C., and McDonald, L. (1964). Effect of homocystine on the blood platelets in vivo and in vitro, related to intravascular thrombosis. Abstracts IV. Congressus Cardiologicus Europaeus. Prague., 1964.

$\longrightarrow$, and - (1966). A new platelet defect in patients with ischaemic heart disease. In Proceedings of the British Cardiac Society. Brit. Heart f., 28, 429.

$\longrightarrow,-$, and Davies, B. (1967a). To be published.

$\longrightarrow,-$, Muir, J., and Davies, B. (1967b). To be published.

Bridges, J. M., Dalby, A. M., Millar, J. H. D., and Weaver, J. A. (1965). An effect of D-glucose on platelet stickiness. Lancet, $1,75$.

Burch, G. E., and DePasquale, N. P. (1962). Hematocrit, blood viscosity and myocardial infarction. Amer. $\mathcal{F}$. Med., 32, 161.

Bygdeman, S., Eliasson, R., and Johnson, S.-R. (1966). Relationship between postoperative changes in adenosinediphosphate induced platelet adhesiveness and venous thrombosis. Lancet, $1,1301$.

Carson, P., McDonald, L., Pickard, S., Pilkington, T., Davies, B., and Love, F. (1966). Effects of clofibrate with androsterone (Atromid) and without androsterone (Atromid-S) on blood platelets and lipids in ischaemic heart disease. Brit. Heart f., 28, 400.

Cassidy, M. (1946). Coronary disease. Lancet, 2, 587.

Chandler, A. B. (1958). In vitro thrombotic coagulation of the blood; a method for producing a thrombus. Lab. Invest., 7, 110.

Clark, E., Graef, I., and Chasis, H. (1936). Thrombosis of the aorta and coronary arteries with special reference to "fibrinoid" lesions. Arch. Path., 22, 183.

Clayton, S., Born, G. V. R., and Cross, M. J. (1963). Inhibition of the aggregation of blood platelets by nucleosides. Nature (Lond.), 200, 138.

- , and Cross, M. J. (1963). The aggregation of blood platelets by catecholamines and by thrombin. $\mathcal{F}$. Physiol. (Lond.), 169, 82 P.

Cohen, A. M., and Shafrir, E. (1965). Carbohydrate metabolism in myocardial infarction: behaviour of blood glucose and free fatty acids after glucose loading. Diabetes, 14, 84.

Conley, C. L., Russell, R. P., Thomas, C. B., and Tumulty, P. A. (1964). Hematocrit values in coronary artery disease. Arch. intern. Med., 113, 170.

Connor, W. E., Hoak, J. C., and Warner, E. D. (1963). Massive thrombosis produced by fatty acid infusion. F. clin. Invest., 42, 860 .

,-- and $-(1965)$. The effects of fatty acids on blood coagulation and thrombosis. Thrombos. Diathes. haemorrh. (Stuttg.), Suppl. 17, p. 89.

- , and Poole, J. C. F. (1961). The effect of fatty acids on the formation of thrombi. Quart. F. exp. Physiol., 46, 1.

Davenport, A. B. (1928). Spontaneous heart rupture-a statistical summary. Amer. F. med. Sci., 176, 62.
Dawber, T. R., Kannel, W. B., Revotskie, N., and Kagan, A. (1962). The epidemiology of coronary heart diseasethe Framingham Enquiry. Proc. roy. Soc. Med., 55, 265.

- Moore, F. E., and Mann, G. V. (1957). 11. Coronary heart disease in the Framingham Study. Amer. $\mathcal{F}$. publ. Hlth, 47, Suppl. April, p. 4.

Dintenfass, L. (1964). Viscosity and clotting of blood in venous thrombosis and coronary occlusions. Circulat. Res., 14.1.

- (1965). Some rheological factors in the pathogenesis of thrombosis. Lancet, 2, 370.

Dole, V. P. (1956). A relation between non-esterified fatty acids in plasma and the metabolism of glucose. $\mathcal{f}$. clin. Invest., 35, 150.

Doll, R., and Hill, A. B. (1954). The mortality of doctors in relation to their smoking habits. Brit. med. F., 1, 1451 .

Duguid, J. B. (1946). Thrombosis as a factor in the pathogenesis of coronary atherosclerosis. F. Path. Bact., 58, 207.

- (1948). Thrombosis as a factor in the pathogenesis of atherosclerosis. F. Path. Bact., 60, 57.

Eberth, J. C., and Schimmelbusch, C. (1886). Experimentelle Untersuchungen über Thrombose. Arch. path. Anat. Physiol., Virchow's, 103, 39.

Emmons, P. R., Harrison, M. J. G., Honour, A. J., and Mitchell, J. R. A. (1965a). Effect of dipyridamole on human platelet behaviour. Lancet, 2, 603.

,,-- , and - (1965b). Effect of a pyrimidopyrimidine derivative on thrombus formation in the rabbit. Nature (Lond.), 208, 255.

Engelberg, H. (1965). Cigarette smoking and the in vitro thrombosis of human blood. F. Amer. med. Ass., 193, 1033.

Evans, G., and Irvine, W. T. (1966). Long-term arterialgraft patency in relation to platelet adhesiveness, biochemical factors, and anticoagulant therapy. Lancet, 2, 353.

Fearnley, G. R. (1965). Fibrinolysis, p. 175. Edward Arnold, London.

French, J. E., MacFarlane, R. G., and Sanders, A. G. (1964). The structure of haemostatic plugs and experimental thrombi in small arteries. Brit. F. exp. Path., 45, 467.

Gaarder, A., Jonsen, J., Laland, S., Hellem, A., and Owren, P. A. (1961). Adenosine diphosphate in red cells as a factor in the adhesiveness of human blood platelets. Nature (Lond.), 192, 531.

Geill, T., Hansen, P. F., and Lund, E. (1960). Dietary fats and thrombosis. Nature (Lond.), 185, 330.

Gertler, M. M., Garn, S. M., and Lerman, J. (1950). The interrelations of serum cholesterol, cholesterol esters and phospholipids in health and in coronary heart disease. Circulation, 2, 205.

- , and White, P. D. (1954). Coronary Heart Disease in Young Adults-A Multidisciplinary Study. Harvard University Press, Cambridge, Massachusetts.

Gross, H., and Sternberg, W. H. (1939). Myocardial infarction without significant lesions of coronary arteries. Arch. intern. Med., 64, 249.

Hammond, E. C., and Horn, D. (1954). The relationship between human smoking habits and death rates. $\mathcal{F}$. Amer. med. Ass., 155, 1316.

Hampton, J. R., and Mitchell, J. R. A. (1966). Effect of aggregating agents on the electrophoretic mobility of human platelets. Brit. med. F., 1, 1074.

Harland, W. A., and Holburn, A. M. (1966). Coronary thrombosis and myocardial infarction, Lancet, 2, 1158.

Harrison, C. V., and Wood, P. (1949). Hypertensive and ischaemic heart disease; a comparative clinical and pathological study. Brit. Heart f., 11, 205. 
Harrison, M. J. G., and Mitchell, J. R. A. (1966). The influence of red blood-cells on platelet adhesiveness. Lancet, 2, 1163.

Haslam, R. J. (1964). Role of adenosine diphosphate in the aggregation of human blood-platelets by thrombin and by fatty acids. Nature (Lond.), 202, 765.

Heberden, W. (1802). Commentaries on the History and Cure of Diseases. Payne, London.

Hedley, O. F. (1939). Analysis of 5,116 deaths reported as due to acute coronary occlusion in Phildelphia, 19331937. Publ. Hlth Rep. (Wash.), 54, 972.

Hirsh, J., and McBride, J. A. (1965). Increased platelet adhesiveness in recurrent venous thrombosis and pulmonary embolism. Brit. med. F., 2, 797.

Hoak, J. C., Poole, J. C. F., and Robinson, D. S. (1963). Thrombosis associated with mobilization of fatty acids. Circulation, 28, 660.

Kannel, W. B., Dawber, T. R., Kagan, A., Revotskie, N., and Stokes, J., III (1961). Factors of risk in the development of coronary heart disease-six year follow-up experience. Ann. intern. Med., 55, 33.

Katz, A. M., McDonald, L., Davies, B., and Edgill, M. (1963). Fibrinolysis and blood coagulation in ischaemic heartdisease. Lancet, 1, 801.

Keen, H., Rose, G., Pyke, D. A., Boyns, D., Chlouverakis, C., and Mistry, S. (1965). Blood-sugar and arterial disease. Lancet, 2, 505.

Kohn, P. M., and Prozan, G. B. (1959). Hyperuricemiarelationship to hypercholesteremia and acute myocardial infarction. F. Amer. med. Ass., 170, 1909.

McDonald, L. (1953). Ischaemic heart disease and peripheral occlusive arterial disease. Brit. Heart f., 15, 101. (1962). Platelet behaviour in thrombotic disorders. Quart. F. Med., 31, 520.

-, Bray, C., Field, C., Love, F., and Davies, B. (1964). Homocystinuria, thrombosis, and the blood-platelets. Lancet, 1, 745.

$\longrightarrow$, and Edgill, M. (1957). Coagulability of the blood in ischaemic heart-disease. Lancet, 2, 457.

- , and - (1958). Dietary restriction and coagulability of the blood in ischaemic heart-disease. Lancet, 1, 996.

$\longrightarrow$, and - (1959). Changes in coagulability of the blood during various phases of ischaemic heart-disease. Lancet, 1, 1115.

$\longrightarrow$, and - (1961). Action of heparin in ischaemic heartdisease. Lancet, 1, 844.

Master, A. M., Gubner, R., Dack, S., and Jaffe, H. L. (1941). Differentiation of acute coronary insufficiency with myocardial infarction from coronary occlusion. Arch. intern. Med., 67, 647.

- Jaffe, H. L., Dack, S., and Grishman, A. (1944). Coronary occlusion, coronary insufficiency, and angina pectoris; a clinical and post-mortem study. Amer. Heart f., 27, 803.

$\longrightarrow,-$, and Pordy, L. (1954). Cardiac and non-cardiac chest pain; a statistical study of "diagnostic" criteria. Ann. intern. Med., 41, 315.

Mayer, G. A. (1964). Blood viscosity in healthy subjects and patients with coronary heart disease. Canad. med. Ass. F., 91, 951.

Mitchell, J. R. A., and Schwartz, C. J. (1965). Arterial Disease. Blackwell Scientific Publications, Oxford.

-, and Sharp, A. A. (1964). Platelet clumping in vitro. Brit. F. Haemat., 10, 78.

Morris, J. N. (1951). Recent history of coronary disease. Lancet, 1, 69.

- (1962). Coronary disease in England. Cardiol. prat. (Firenze), 13, 85.

-, and Crawford, M. D. (1961). Atherosclerosis and coronary (ischaemic) heart-disease. Lancet, 1, 47. $\longrightarrow,-$, and Heady, J. A. (1961). Hardness of local watersupplies and mortality from cardiovascular disease in the County Boroughs of England and Wales. Lancet, 1, 860.

Muri, J. W. (1956). The coronary circulation in myocardial infarction. Acta med. scand., Suppl. 319, p. 112.

Murphy, E. A., and Mustard, J. F. (1962). Coagulation tests and platelet economy in atherosclerotic and control subjects. Circulation, 25, 114.

-, Rowsell, H. C., Hegardt, B., Downie, H. G., and Mustard, J. F. (1963). Effect of fatty acids on blood coagulation, platelet economy, and thrombosis. Circulation, 28, 666.

Mustard, J. F., Lotz, F., Murphy, E. A., and Rowsell, H. C. (1964). ADP platelet thrombosis. F. clin. Invest., 43, 1305.

- and Murphy, E. A. (1962). Effect of different dietary fats on blood coagulation, platelet economy, and blood lipids. Brit. med.F., 1, 1651.

- , and - (1963a). Effect of smoking on blood coagulation in platelet survival in man. Brit. med. F., 1,846 .

- , and - (1963b). Blood platelet economy during moderate and intensive heparin therapy. Blood, 22, 1.

$\longrightarrow$ - - Rowsell, H. C., and Downie, H. G. (1962). Factors influencing thrombus formation in vivo. Amer. f. Med., 33, 621.

Nestel, P. J. (1961). A note on platelet adhesiveness in ischaemic heart disease. F. clin. Path., 14, 150.

Nikkilä, E. A., Miettinen, T. A., Vesenne, M-R., and Pelkonen, R. (1965). Plasma-insulin in coronary heart-disease. Lancet, 2, 508.

O’Brien, J. R. (1962). Platelet aggregation. Part 1. Some effects of the adenosine phosphates, thrombin, and cocaine upon platelet adhesiveness. F. clin. Path., 15, 446.

- (1964). A comparison of platelet aggregation produced by seven compounds and a comparison of their inhibitors. f. clin. Path., 17, 275.

Ogston, D., and Fullerton, H. W. (1965). Plasma fibrinolytic activity following recent myocardial and cerebral infarction. Lancet, 2, 99.

Oliver, M. F., and Boyd, G. S. (1959). Effect of bilateral ovariectomy on coronary-artery disease and serum-lipid levels. Lancet, 2, 690.

Ostrander, L. D., and Weinstein, B. J. (1964). Electrocardiographic changes after glucose ingestion. Circulation, 30, 67.

Peters, N., and Hales, C. N. (1965). Plasma-insulin concentrations after myocardial infarction. Lancet, 1, 1144.

Pickering, G. (1965). Foreword to Arterial Disease. By J. R. A. Mitchell and C. J. Schwartz. Blackwell Scientific Publications, Oxford.

Poole, J. C. F. (1955). The effect of certain fatty acids on the coagulation of plasma in vitro. Brit. F. exp. Path., 36, 248.

- , and French, J. E. (1961). Thrombosis. F. Atheroscler. Res., 1, 251.

Rokitansky, C. von (1852). A Manual of Pathological Anatomy, Vol. 4. Sydenham Society, London.

Rose, G. (1964). Familial patterns in ischaemic heart disease. Brit. F. prev. soc. Med., 18, 75.

Ross Russell, R. W. (1961). Observations on the retinal blood-vessels in monocular blindness. Lancet, $2,1422$.

Schmid, H. J., Jackson, D. P., and Conley, C. L. (1962). Mechanism of action of thrombin on platelets. $\mathcal{F}$. clin. Invest., 41, 543.

Seaman, A. J., Lutcher, C. L., Moffatt, C. A., and Hueber, B. E. (1967). Induced intravascular thrombembolic phenomena. Direct observation in the living extracorporeal eye. Arch. intern. Med., 119, 600. 
Skovborg, F., Nielsen, Aa. V., Schlichtkrull, J., and Ditzel, J. (1966). Blood-viscosity in diabetic patients. Lancet, $1,129$.

Slack, J., and Evans, K. A. (1966). The increased risk of death from ischaemic heart disease in first degree relatives of 121 men and 96 women with ischaemic heart disease. f. med. Genet., 3, 239.

-, Seymour, J., McDonald, L., and Love, F. (1964). Lipoprotein-lipase levels and platelet stickiness in patients with ischaemic heart-disease and in controls, distinguishing those with an affected first-degree relative. Lancet, 2, 1033.

Snow, P. J. D., Morgan Jones, A., and Daber, K. S. (1955). Coronary disease: a pathological study. Brit. Heart $\mathcal{F}$., $17,503$.

Soloff, L. A., and Schwartz, H. (1966). Relationship between glucose and fatty acid in myocardial infarction. Lancet, 1, 449.

Spain, D. M., and Bradess, V. A. (1960). The relationship of coronary thrombosis to coronary atherosclerosis and heart disease. (A necropsy study covering a period of 25 years.) Amer. f. med. Sci., 240, 701.

Thomas, C. B., and Cohen, B. H. (1955). The familial occurrence of hypertension and coronary artery disease, with observations concerning obesity and diabetes. Ann. intern. Med., 42, 90.
Thomas, D. P., Gurewich, V., and Ashford, T. P. (1966). Platelet adherence to thromboemboli in relation to the pathogenesis and treatment of pulmonary embolism. Nerv Engl. F. Med., 274, 953.

Thorp, J. M. (1962). Experimental evaluation of an orally active combination of androsterone with ethyl chlorophenoxyisobutyrate. Lancet, 1, 1323.

Vallance-Owen, J., and Ashton, W. L. (1963). Cardiac infarction and insulin antagonism. Lancet, 1, 1226.

Wahlberg, F. (1962). The intravenous glucose tolerance test in atherosclerotic disease with special reference to obesity, hypertension, diabetic heredity, and cholesterol values. Acta med. scand., 171, 1.

Warren, B. A. (1964). Fibrinolytic activity of vascular endothelium. Brit. med. Bull., 20, 213.

Wright, H. P. (1941). The adhesiveness of blood platelets in normal subjects with varying concentrations of anticoagulants. F. Path. Bact., 53, 255.

- (1942). Changes in adhesiveness of blood platelets following parturition and surgical operations. $\mathcal{F}$. Path. Bact., 54, 461 .

Yudkin, J. (1964). Dietary fat and dietary sugar in relation to ischaemic heart-disease and diabetes. Lancet, 2, 4.

Zucker, M. B., and Borrelli, J. (1962). Platelet clumping produced by connective tissue suspensions and by collagen. Proc. Soc. exp. Biol. (N.Y.), 109, 779. 